\title{
Ginkgetin exerts growth inhibitory and apoptotic effects on osteosarcoma cells through inhibition of STAT3 and activation of caspase-3/9
}

\author{
MIN XIONG*, LIN WANG*, HUA-LONG YU, HENG HAN, DAN MAO, JIE CHEN, YUN ZENG, NING HE, \\ ZHI-GANG LIU, ZHI-YONG WANG, SHOU-JIA XU, LE-YUN GUO and YONG-AN WANG
}

Department of Orthopedics Institute, Affiliated Dongfeng Hospital, Hubei University of Medicine,

Shiyan, Hubei 442008, P.R. China

Received June 18, 2015; Accepted July 13, 2015

DOI: 10.3892/or.2015.4427

\begin{abstract}
Osteosarcoma is composed of tumor osteoblasts and bone-like tissues, with malignant tumors originating from osteogenesis organization. Osteosarcoma is a primary malignant bone tumor. Invasion and metastasis of osteosarcoma affect the prognosis of patients. However, effective therapeutic treatments remain to be identified. The aim of the present study was to investigate the possible inhibitory and apoptotic effects of ginkgetin in osteosarcoma cells. 3.3-(4,5-Dimethylthiazol2-yl)-2,5-diphenyltetrazolium bromide (MTT) and lactate dehydrogenase (LDH) assays were used to determine the effect ginkgetin exerted on the growth of osteosarcoma cells. Flow cytometry was used to determine cell apoptosis. STAT3 protein expression and activation of caspase-3/9 were measured using western blot analysis and the MTT and LDH assays, respectively. The results showed that ginkgetin inhibited cell growth and induced cell cytotoxicity in osteosarcoma cells in a dose-dependent manner. Treatment with ginkgetin significantly activated the apoptosis of osteosarcoma cells in a concentration-dependent manner. The anticancer activity of ginkgetin significantly inhibited STAT3 and promoted caspase-3/9 activation in osteosarcoma cells. The findings demonstrated that ginkgetin exerts growth inhibitory and apoptotic effects on osteosarcoma cells through the inhibition of STAT3 and activation of caspase-3/9.
\end{abstract}

\section{Introduction}

Osteosarcoma comprises tumor osteoblasts and bone-like tissue, with malignant tumors originating for osteogenesis

Correspondence to: Dr Yong-an Wang, Department of Orthopedics Institute, Affiliated Dongfeng Hospital, Hubei University of Medicine, 16 Daling Road, Shiyan, Hubei 442008, P.R. China

E-mail: yonganwang@yeah.net

*Contributed equally

Key words: ginkgetin, osteosarcoma, STAT3, caspase-3/9 organization. Osteosarcoma is a primary malignant bone tumor (1). The disease is characterized by a high degree of tumor malignancy and poor prognosis, while the 3- to 5-year survival rate after amputation is only $5-20 \%$ (1). Advances in treatment such as chemotherapy and surgery have improved the patient survival rate. However, even with combinatorial treatment comprising chemotherapy and surgery, the 5-year survival rate remains at $55-68 \%$ (2). Metastatic spread is the main cause for the poor prognosis of osteosarcoma. However, transfer therapies currently available are not satisfactory. Additionally, the side effects of systemic chemotherapy cause damage to internal organs of the human body $(3,4)$. Invasion and metastasis of osteosarcoma seriously affect the quality of life and prognosis of patients. Gene therapy remains a hotspot in the study of osteosarcoma, while the specific mechanism involved remains to be determined. Gene therapy continues to be considered an effective form of treatment for osteosarcoma (5).

Ginkgo biloba is the only species in the Ginkgo genus of the family of ginkgoaceae, and comprises the components ginkgolides and bilobalide, which are present in the leaf and velamen of the plant (6). Ginkgetin is a biflavone isolated from the ginkgo biloba leaves (7) and its effects on cyclooxygenase and anti-inflammatory activity in the body have been previously investigated (8). Ginkgetin exerts anti-inflammatory, antioxidant, as well as anticancer effects $(6,8,9)$. Thus, in the present study, the possible inhibitory and apoptotic effects of ginkgetin in osteosarcoma cells, as well as the underlying mechanisms involved were investigated.

\section{Materials and methods}

Chemical reagents. Dulbecco's modified Eagle's medium/ Ham's F-12 medium (DMEM/F-12) and fetal bovine serum (FBS) were obtained from Invitrogen (Grand Island, NY, USA). Trypsin, 3.3-(4,5-dimethylthiazol-2-yl)-2,5-diphenyltetrazolium bromide (MTT) and lactate dehydrogenase (LDH) were obtained from the Beyotime Institute of Biotechnology (Haimen, Jiangsu, China). The Annexin V-FITC/propidium iodide (PI) kit was obtained from BD Biosciences (San Jose, CA, USA). 
Cell culture and cell proliferation assay. The present study was approved by the regional Ethics Committee of the Affiliated Dongfeng Hospital, Hubei University of Medicine (Hubei, China). Written informed consent was obtained from all the patients. Giant cell tumor samples were collected from patients at the Affiliated Dongfeng Hospital, Hubei University of Medicine. The samples were separated and sectioned in medium containing DMEM/F-12, supplemented with $10 \%$ FBS and $100 \mathrm{U} / \mathrm{ml}$ penicillin and $100 \mathrm{mg} / \mathrm{ml}$ streptomycin. The giant cell tumor samples were digested with $0.01 \%$ trypsin (Beyotime Institute of Biotechnology) at room temperature for 10-30 min. The samples were transferred into $25-\mathrm{cm}^{2}$ flasks, and the cell samples were incubated at $37^{\circ} \mathrm{C}$ in a water-saturated atmosphere of $95 \%$ air and $5 \% \mathrm{CO}_{2}$. The culture medium was replaced half with fresh complete medium every 2 days. Primary cultures were subcultured and stored in liquid nitrogen at $37^{\circ} \mathrm{C}$ in a water-saturated atmosphere of $95 \%$ air and $5 \% \mathrm{CO}_{2}$ until cell confluence was reached.

MTT assay. To determine cell growth, osteosarcoma cells were seeded in a 96-well plate $\left(1 \times 10^{3}\right.$ cells/well) and cultured with ginkgetin $(0,5,10,20,30,40,50$ and $60 \mu \mathrm{M})$ for $24 \mathrm{~h}$ at room temperature of $37^{\circ} \mathrm{C}$ in a humidified atmosphere of $5 \% \mathrm{CO}_{2}$. MTT solution $(20 \mu \mathrm{l})$ was added to each well and the samples were incubated for $4 \mathrm{~h}$ at a temperature of $37^{\circ} \mathrm{C}$ in a humidified atmosphere of $5 \% \mathrm{CO}_{2}$. Dimethylsulfoxide (DMSO) solution ) $150 \mu \mathrm{l}$ ) was added to each well followed by gentle agitation for $20 \mathrm{~min}$. The cell growth of each well was measured at $\lambda=570 \mathrm{~nm}$ using a multiscanner (XL-818; Bio-Tek, Winooski, VT, USA).

LDH assay. To determine cytotoxicity, osteosarcoma cells were seeded in a 96-well plate $\left(1 \times 10^{3}\right.$ cells/well) and cultured with ginkgetin $(0,5,10,20,30,40,50$ and $60 \mu \mathrm{M})$ for $24 \mathrm{~h}$ at a room temperature of $37^{\circ} \mathrm{C}$ in a humidified atmosphere of $5 \% \mathrm{CO}_{2}$. LDH solution $(100 \mu \mathrm{l})$ was added into each well and incubated for $30 \mathrm{~min}$ at a temperature of $37^{\circ} \mathrm{C}$ in a humidified atmosphere of $5 \% \mathrm{CO}_{2}$. The cell growth of each well was measured at $\lambda=490 \mathrm{~nm}$ using a multiscanner (XL-818).

Flow cytometry. To determine cell apoptosis, osteosarcoma cells were seeded in a 6 -well plate $\left(1.5 \times 10^{6}\right.$ cells/well $)$ and cultured with ginkgetin $(0,20,30$ and $40 \mu \mathrm{M})$ for $24 \mathrm{~h}$ at a room temperature of $37^{\circ} \mathrm{C}$ in a humidified atmosphere of $5 \%$ $\mathrm{CO}_{2}$. Annexin-V/FITC $(10 \mu \mathrm{l})$ and $10 \mu \mathrm{l}$ of PI were added into each well and incubated for $30 \mathrm{~min}$ in the dark. Cell apoptosis was detected using flow cytometry $\left(\mathrm{EPICS}^{\circledR}\right.$ Altra $^{\mathrm{TM}}$, Brea, CA, USA).

Western blot analysis. Osteosarcoma cells were seeded in a 6 -well plate $\left(1.5 \times 10^{6}\right.$ cells/well) and cultured with ginkgetin $(0,20,30$ and $40 \mu \mathrm{M})$ for $24 \mathrm{~h}$ at a room temperature of $37^{\circ} \mathrm{C}$ in a humidified atmosphere of $5 \% \mathrm{CO}_{2}$. The osteosarcoma cells were resuspended using lysis buffer containing RIPA lysis buffer (Beyotime Institute of Biotechnology) for $30 \mathrm{~min}$ on ice. The protein concentration was determined with Coomassie blue staining. Protein sample $(20 \mu \mathrm{g})$ was used to load the sodium dodecyl sulfate (SDS)-polyacrylamide gel and the samples were transferred onto a cellulose nitrate film (Hybond ${ }^{\mathrm{TM}}-\mathrm{C}$; Amersham Biosciences, Piscataway,<smiles>O=c1cc(-c2ccc(O)c(-c3c(O)cc(O)c4c(=O)cc(-c5ccc(O)cc5)oc34)c2)oc2cc(O)cc(O)c12</smiles>

Figure 1. The chemical structure of ginkgetin.

NJ, USA). The cellulose nitrate film was blocked with trisbuffered saline (TBS) containing 5\% non-fat milk to block non-specific binding sites. The cellulose nitrate film was incubated with anti-p-STAT3 (phosphorylation-STAT3, 1:1,000), anti-Bcl-2 (1:2,000), anti-Bcl-xL (1:1,000), anti-cyclin D1 $(1: 1,000)$, anti-survivin $(1: 1,500)$, anti-total PARP $(1: 2,000)$ (all from Santa Cruz Biotechnology, Inc., Santa Cruz, CA, USA) and anti- $\beta$-actin (1:500; Sangon Biotech, Shanghai, China) overnight at $4^{\circ} \mathrm{C}$. The cellulose nitrate film was washed three times with $0.1 \%(\mathrm{v} / \mathrm{v})$ Tween-20 in tris-buffered saline (TTBS) and incubated with the secondary antibody (1:5,000; Santa Cruz Biotechnology, Inc.). The film was subsequently washed using an ECL Advanced Western Blot Detection kit (Beyotime Biotech, Nanjing, China). The resultant bands were detected using the gel imaging system (GDS8000; Ultra Violet Products, Upland, CA, USA).

Caspase-3/9 activation. Osteosarcoma cells were seeded in a 6 -well plate $\left(1.5 \times 10^{6}\right.$ cells/well) and cultured with ginkgetin $(0,20,30$ and $40 \mu \mathrm{M})$ for $24 \mathrm{~h}$ at a room temperature of $37^{\circ} \mathrm{C}$ in a humidified atmosphere of $5 \% \mathrm{CO}_{2}$. Osteosarcoma cells were resuspended using lysis buffer containing RIPA lysis buffer for $30 \mathrm{~min}$ on ice. The protein concentration was determined with Coomassie blue staining. The caspase-3/9 activation was visualized using fluorescence and was detected at the wavelength of $405 \mathrm{~nm}$ with the caspase- 3 and -9 colorimetric assay kits (Beyotime Institute of Biotechnology).

Statistical analysis. Data were presented as means \pm SD and the degree of significance was analyzed by the Student's t-test. Differences were considered to indicate a statistically significant result at $\mathrm{P}=0.05$.

\section{Results}

Inhibitory growth effect of ginkgetin in osteosarcoma cells. To identify the growth inhibitory effect of ginkgetin in osteosarcoma cells, the cell growth was measured using an MTT assay. The structure of ginkgetin is shown in Fig. 1. Ginkgetin was identified as exerting a potential anticancer effect on osteosarcoma cells by inhibiting the growth of osteosarcoma cells in a dose-dependent manner. Thus, $35.5 \mu \mathrm{M}$ of ginkgetin exerted a $50 \%$ inhibitory cell growth effect on osteosarcoma cells (Fig. 2). 


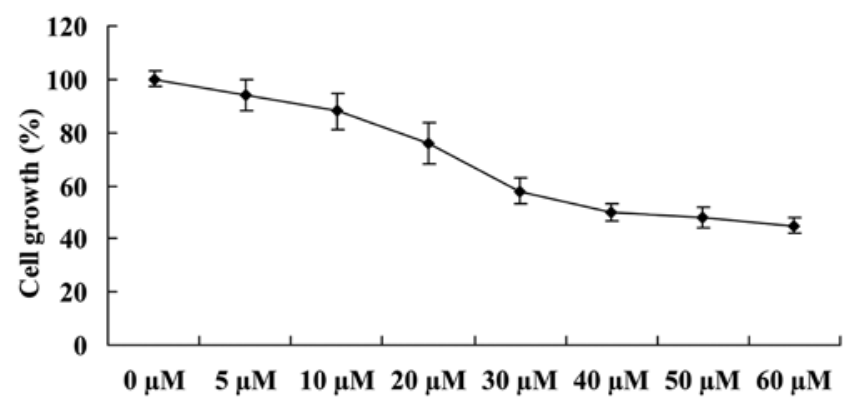

Figure 2. Growth inhibitory effect of ginkgetin in osteosarcoma cells.

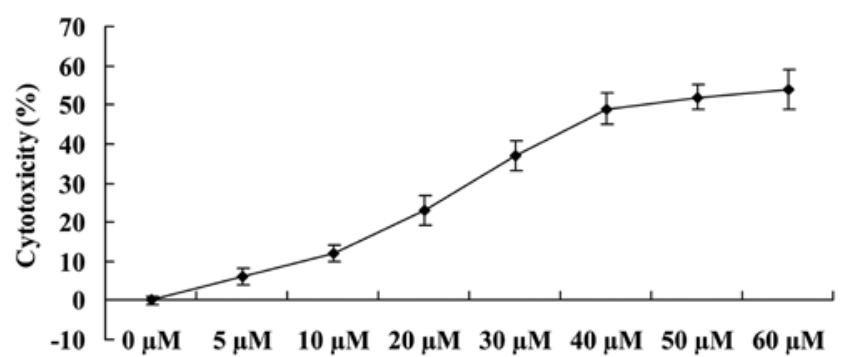

Figure 3. Growth inhibitory effect of ginkgetin results in an increase in the cytotoxicity of osteosarcoma cells.

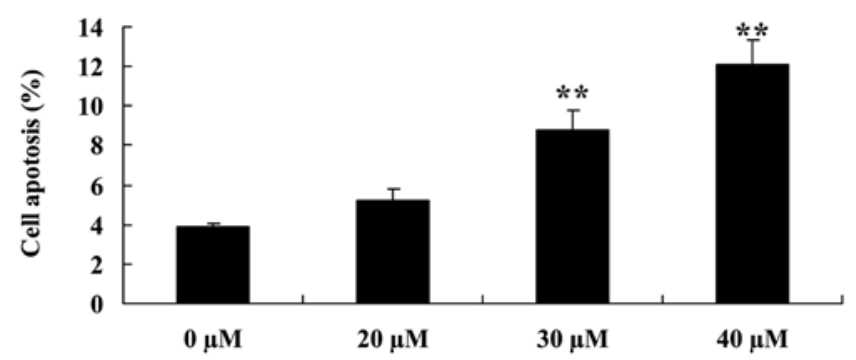

Figure 4. Apoptotic effect of ginkgetin in osteosarcoma cells. ${ }^{* *} \mathrm{P}<0.01$ compared to the $0 \mu \mathrm{M}$ ginkgetin-treated group.

Growth inhibitory effect of ginkgetin results in an increase in the cytotoxicity of osteosarcoma cells. We examined whether the growth inhibitory effects of ginkgetin increased the cytotoxicity of osteosarcoma cells. As shown in Fig. 3, ginkgetin effectively induced the cytotoxicity of osteosarcoma cells in a dose-dependent manner. Thus, $41.2 \mu \mathrm{M}$ of ginkgetin resulted in a 50\% increase of cytotoxicity of osteosarcoma cells, compared to the $0 \mu \mathrm{M}$ ginkgetin-treated group.

Apoptotic effect of ginkgetin on osteosarcoma cells. To examine the apoptotic effect of ginkgetin on osteosarcoma cells, flow cytometry was used to analyze the apoptosis of osteosarcoma cells. Osteosarcoma cells were treated with ginkgetin at $0,20,30$ and $40 \mu \mathrm{M}$. The results showed that ginkgetin markedly induced the apoptosis of osteosarcoma cells in a concentration-dependent manner, suggesting 30 or $40 \mu \mathrm{M}$ of ginkgetin induced apoptosis of osteosarcoma cells, and the result was statistically significant (Fig. 4).
A
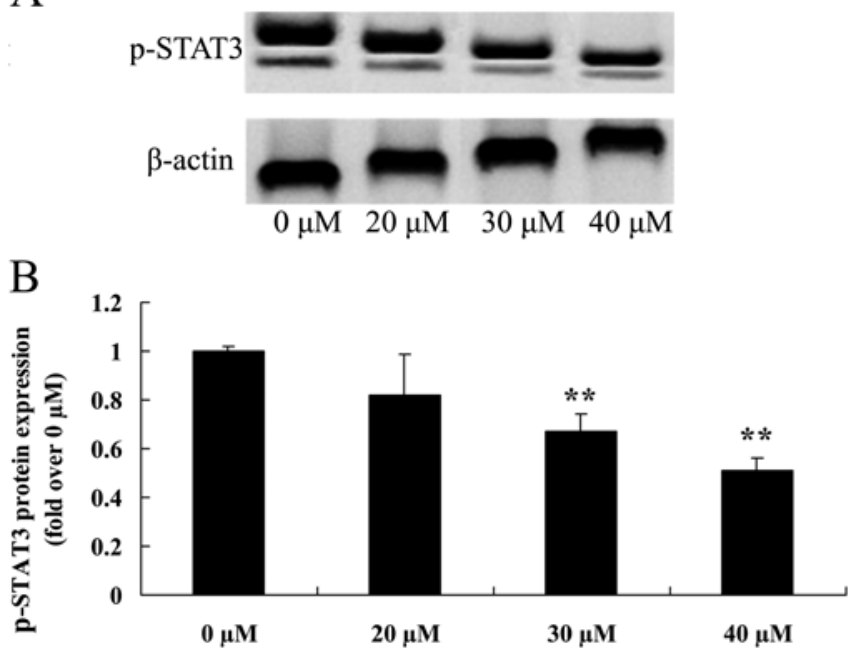

Figure 5. Growth inhibitory effect of ginkgetin suppresses STAT3 protein expression. (A) Western blot analysis and (B) statistical analysis of the STAT3 protein expression of osteosarcoma cells. ${ }^{* *} \mathrm{P}<0.01$ compared to the $0 \mu \mathrm{M}$ ginkgetin-treated group.
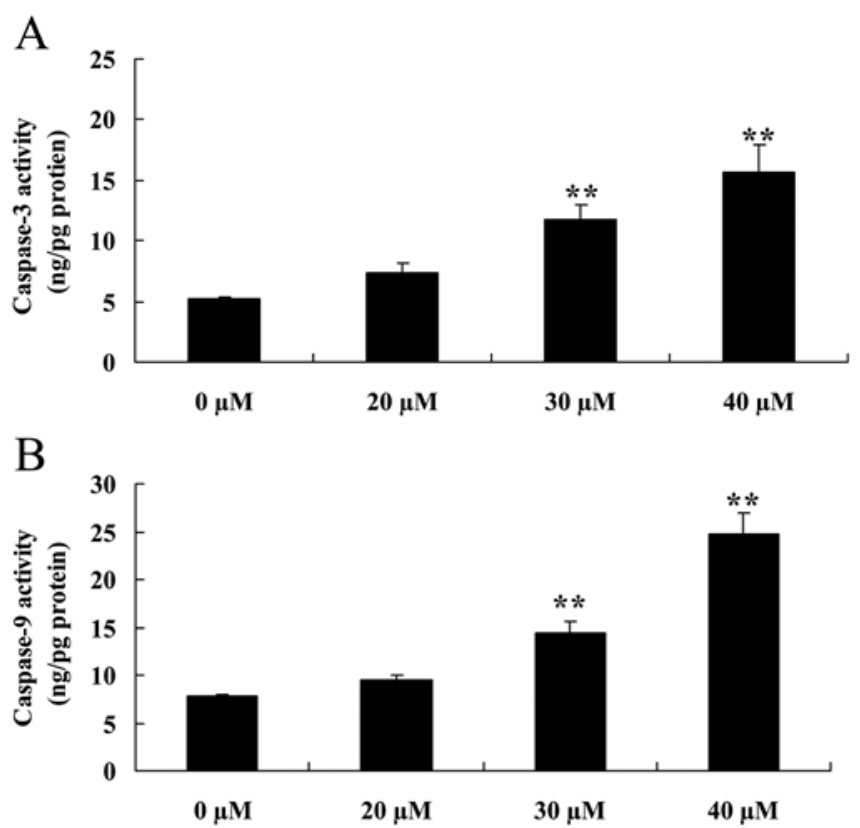

Figure 6. Inhibitory effect of ginkgetin induces the caspase-3/9 activation of osteosarcoma cells. Effects of ginkgetin induce (A) caspase-3 and (B) caspase- 9 activation of osteosarcoma cells. ${ }^{* *} \mathrm{P}<0.01$ compared to the $0 \mu \mathrm{M}$ ginkgetin-treated group.

Inhibitory growth effect suppresses STAT3 of osteosarcoma cells. As shown in Fig. 5A and B, pretreatment with ginkgetin markedly suppressed the p-STAT3 protein expression of osteosarcoma cells in a dose-dependent manner. Thus, 30 or $40 \mu \mathrm{M}$ of ginkgetin suppressed the p-STAT3 protein expression in osteosarcoma cells, and the result was statistically significant.

Inhibitory effect of ginkgetin induces caspase-3/9 activation of osteosarcoma cells. To confirm the effect of the caspase3/9 pathway on the inhibition of ginkgetin on osteosarcoma 
A

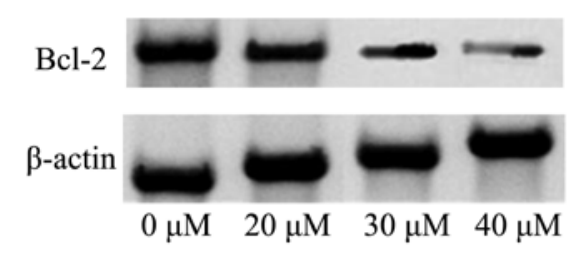

C

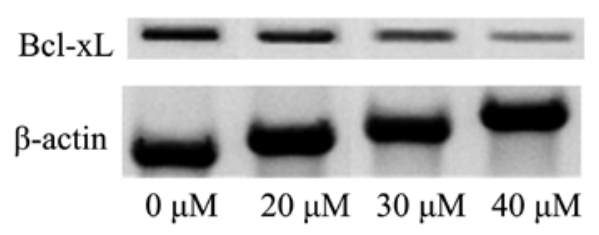

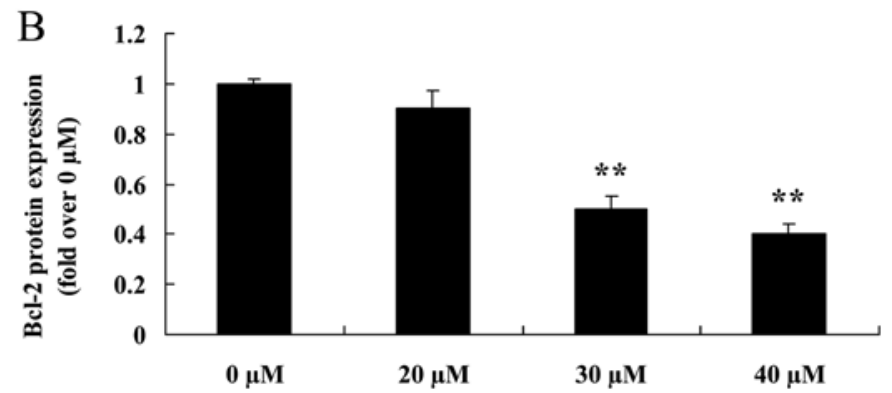

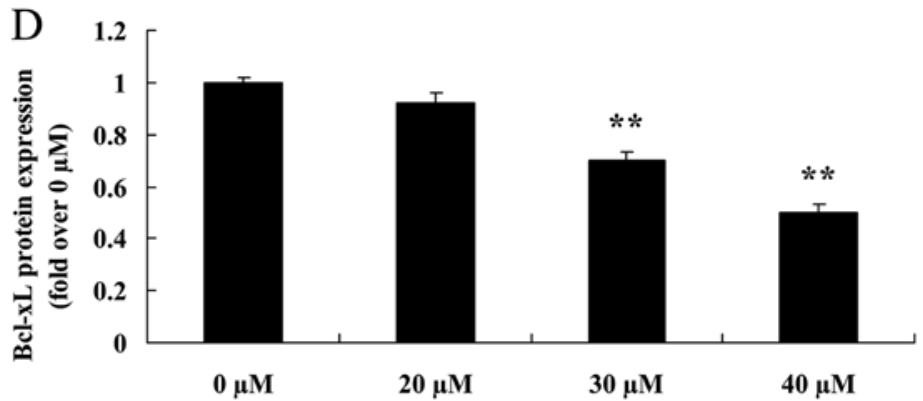

Figure 7. Growth inhibitory effect of ginkgetin suppresses Bcl-2 and Bcl-xL of osteosarcoma cells. Effects of ginkgetin on the protein expression of Bcl-2 and $\mathrm{Bcl}-\mathrm{xL}$ were assessed using (A and $\mathrm{C}$ ) western blot analysis and (B and $\mathrm{D}$ ) statistical analysis for osteosarcoma cells. ${ }^{* *} \mathrm{P}<0.01 \mathrm{compared}$ to the $0 \mu \mathrm{M}$ ginkgetin-treated group.

A

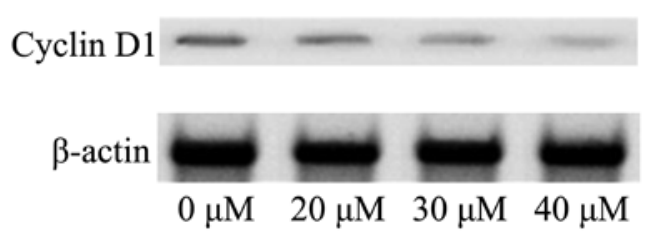

B

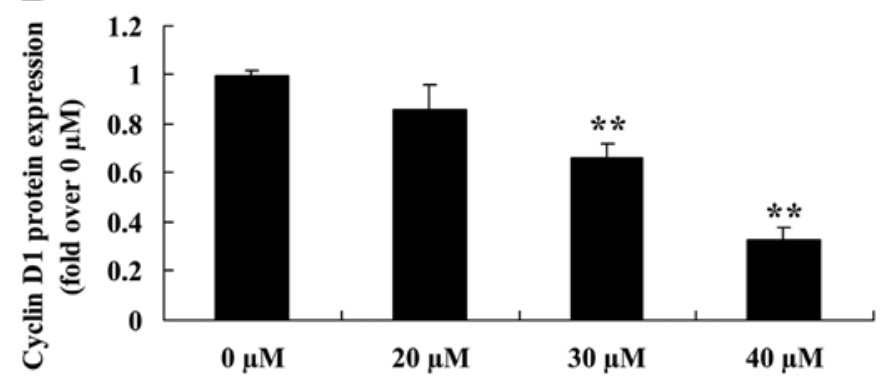

Figure 8. Growth inhibitory effect of ginkgetin suppresses cyclin D1 in osteosarcoma cells. Effects of ginkgetin on cyclin D1 protein expression were assessed using (A) western blot analysis and (B) statistical analysis for osteosarcoma cells. ${ }^{* *} \mathrm{P}<0.01$ compared to the $0 \mu \mathrm{M}$ ginkgetin-treated group.

cells, osteosarcoma cells were treated with ginkgetin and the activation of caspase-3/9 was measured. The results showed a marked increase in the activation of caspase- 3 and -9 of osteosarcoma cells treated with ginkgetin (30 or $40 \mu \mathrm{M}$, Fig. 6).

Growth inhibitory effect of ginkgetin suppresses Bcl-2 and Bcl-xL in osteosarcoma cells. Regulatory proteins such as $\mathrm{Bcl}-2$ and $\mathrm{Bcl}-\mathrm{xL}$, are involved in the apoptotic signaling pathway (10). Fig. 7A and $\mathrm{C}$ shows the suppression of the two proteins following treatment with ginkgetin. Fig. 7B and D shows that 30 or $40 \mu \mathrm{M}$ of ginkgetin markedly reduced the protein expression of $\mathrm{Bcl}-2$ and $\mathrm{Bcl}-\mathrm{xL}$ in osteosarcoma cells in a dose-dependent manner.

Growth inhibitory effect of ginkgetin suppresses cyclin D1 in osteosarcoma cells. Induced apoptotic regulatory protein cyclin D1 was assessed using western blot analysis (Fig. 8A). Treatment with ginkgetin ( 30 or $40 \mu \mathrm{M}$ ) markedly reduced the protein expression of cyclin D1 of osteosarcoma cells (Fig. 8B).
Growth inhibitory effect of ginkgetin suppresses survivin in osteosarcoma cells. We also measured the induced apoptotic regulatory protein survivin, using western blot analysis. The expression of survivin protein was suppressed by treatment with 30 or $40 \mu \mathrm{M}$ of ginkgetin in osteosarcoma cells (Fig. 9).

Growth inhibitory effect of ginkgetin suppresses total PARP of osteosarcoma cells. To assess whether the growth inhibitory effect of ginkgetin suppressed total PARP in osteosarcoma cells, total PARP protein expression was measured using western blot analysis. The results revealed that the total PARP protein expression was significantly suppressed following the treament of ginkgetin at 30 or $40 \mu \mathrm{M}$ in osteosarcoma cells (Fig. 10).

\section{Discussion}

Osteogenesis is one of the most common malignant osseous tumors. Osteogenesis is characterized by tumor cells that 

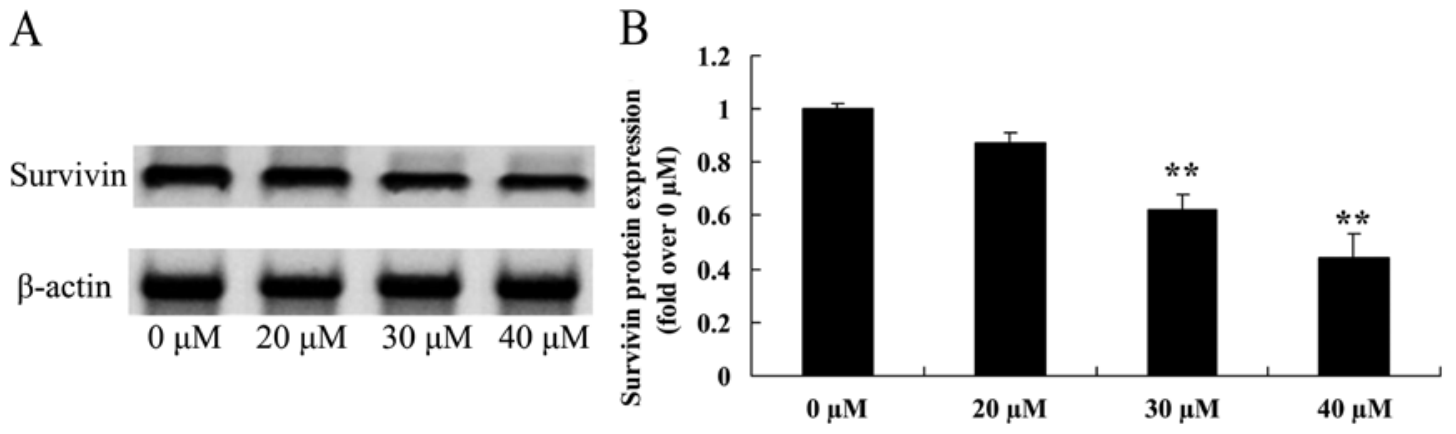

Figure 9. Anticancer effects of ginkgetin inhibit the growth of survivin of osteosarcoma cells. Anticancer effects of ginkgetin inhibits the growth of survivin protein expression using western blot analysis (A) and statistical analysis of survivin protein expression (B) of osteosarcoma cells. ${ }^{* *} \mathrm{P}<0.01$ compared with $0 \mu \mathrm{M}$ of ginkgetin-treated group.

A

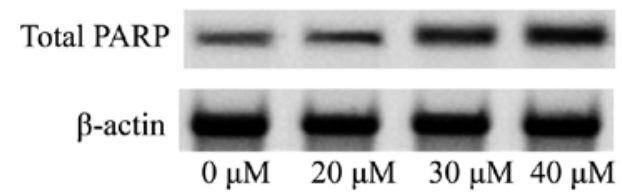

B

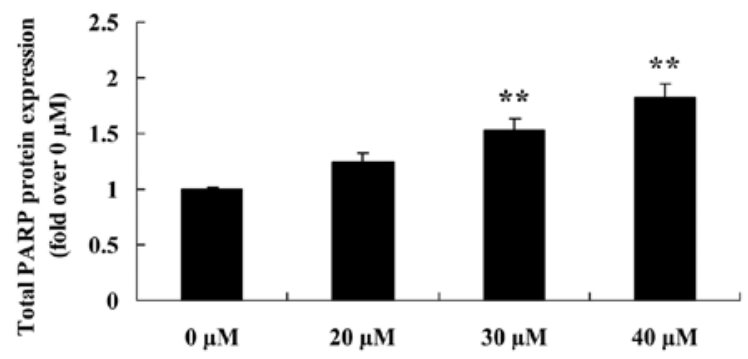

Figure 10. Anticancer effects of ginkgetin inhibits the growth of total PARP of osteosarcoma cells. Anticancer effects of ginkgetin inhibits the growth of total PARP protein expression using (A) western blot analysis and (B) statistical analysis of total PARP protein expression of osteosarcoma cells. ${ }^{* *} \mathrm{P}<0.01$ compared with $0 \mu \mathrm{M}$ of ginkgetin-treated group.

produce osteoid matrix, which is produced directly by the sarcoma of osteoblasts, bone tissue and new bone, and is simultaneously combined with osteogenesis and bone destruction in different proportions, resulting in osteogenesis and osteolysis types often occurring in lung metastasis (1). Osteosarcoma is highly malignant and has a poor prognosis, and even with surgical treatment combined with chemotherapy, the 5-year survival rate is only $55-68 \%$ (11). The main reason for the poor prognosis is early metastatic spread of osteosarcoma. However, current anti-metastatic therapy remains unsatisfactory, with side-effects of systemic chemotherapy causing damage to internal organs of the human body. Additionally, surgical treatment is usually considered unacceptable by patients due to potential loss of limb (12). Therefore, identification of treatment for osteosarcoma is imperative. You et al have identified that ginkgetin induces the apoptosis of PC-3 prostate cancer cells through the activation of caspase (10). In the present study, 30 or $40 \mu \mathrm{M}$ of ginkgetin inhibited cell growth, increased cytotoxicity and induced the cell apoptosis of osteosarcoma cells. Thus, a new potential anticancer effect of ginkgetin has been identified involving the inhibition of cell growth and induction of apoptosis of osteosarcoma cells. However, the mechanisms underlying its anticancer activities remain to be elucidated.

SATA3 is a key signal transduction and transcriptional activation protein found in the body. The STAT3 coding gene in human is located in chromosome 12 (13). The STAT3 signaling pathway is a signal transduction system that is transduced from the membrane to the nucleus, through the activation of the receptor tyrosine kinase STAT3 target genes (14). STAT3 is mainly stimulated through tyrosine phosphorylation, triggering the activation of STAT3 receptor, thereby forming the cytoplasm of homologous or heterologous dimers (14). The STAT3 dimer enters the nucleus, and combines to the specific gene promoter, thereby inducing gene expression (15). In normal tissue cells, the expression of STAT3 is rapid and short, while in a variety of malignant tumors, such as liver cancer, gastric cancer, lung cancer, head and neck squamous cell carcinoma, breast and prostate cancer, STAT3 expression is characterized by persistent activation and a high expression. Additionally, its expression level is closely associated with the degree of malignancy and tumor prognosis (16). Osteosarcoma organization is highly expressed in STAT3, while the expression of STAT3 is associated with tumor staging as well as tumor presence of soft tissue infiltration (17). STAT3 signal plays an important role in the occurrence and development of osteosarcoma (17). In the present study, we elucidated the anticancer mechanism of ginkgetin against osteosarcoma cells through the suppression of p-STAT3 expression. Additionally, Jeon et al reported that ginkgetin inhibits the cell growth by suppressing STAT3 protein expression in human prostate DU-145 cancer cells (18).

Our mechanistic study indicates that ginkgetin reduced the activation of caspase- 3 and -9 in osteosarcoma cells. Caspase-3/9 is a cysteine protease that is distributed in tissues and cell lines of bone and cartilage. It is involved in the apoptosis mechanism due to its structure domain having a FADD-like death effect, proceeding into the death domain 
and FADD effect structure. Caspase-3/9 is involved in apoptosis primarily through the death-induced signal complex. The caspase protease family is situated in a central position in the cell apoptotic process, and is directly involved in early apoptosis, signal transmission and late apoptosis, including caspase-3/9, which is identified in the top of the cascade reaction. The expression of caspase-3/9 reflects the level of the cell apoptotic reaction as well as the existence of initiation of apoptotic factors. Su et al have identified the ginkgetin-induced apoptosis of human ovarian adenocarcinoma cells via the activation of caspase-3 (6). Thus, a possible anticancer effect of apoptosis occurring following activation of caspase-3/9 in osteosarcoma cells has been identified.

Mitochondrial cell apoptotic pathways are regulated by Bcl-2 family proteins $(19,20)$. The Bcl-2 family is a polygenic family comprising at least 25 family members in mammals. It includes subfamilies such as the Bcl-2 subfamily, whose members Bcl-2, Bcl-xl, Mcl-1, A1 and Bcl-w inhibit cell apoptosis; the Bax subfamily, whose members Bax and Bak promote cell apoptosis; and the BH3-only protein families, which promote cell apoptosis. Bcl-2 subfamily members including Bcl-xl, Mcl-1 and A1, can be used as targets for gene therapy for tumors of the digestive system $(20,21)$. Our results revealed that ginkgetin has antitumor activity against the reduction of the protein expression of Bcl-2 and $\mathrm{Bcl}-\mathrm{xL}$ in osteosarcoma cells in a dose-dependent manner. Jeon et al also reported that ginkgetin inhibits cell growth through anti-apoptotic proteins (Bcl-2 and Bcl-xL) in prostate DU-145 cancer cells (18). This result shows that $\mathrm{Bcl}-2$ and $\mathrm{Bcl}-\mathrm{xL}$ are biomarkers involved in the anticancer effect of ginkgetin on osteosarcoma.

Cyclin D1 is considered an oncogene whose encoded protein accelerates the regulation of cell proliferation. However, overexpression of this oncogene as well as loss of control leads to an abnormal cell cycle, thus causing cancer (22). The expression of survivin protein in the human body and its biological effects are not expressed in healthy adult tissue except for the outer thymus, placenta, $\mathrm{CD} 34^{+}$stem and epithelial cells on the basal portion of the colon (23). However, survivin has been shown to be expressed in lung, breast and colon cancer, and soft tissue sarcoma and malignant cells in the blood. In addition, retrieval of the wide gene expression profile confirmed that compared with normal tissue, there were statistically significant differences in survivin expression (19). We observed that 30 or $40 \mu \mathrm{M}$ of ginkgetin treatment markedly reduced the protein expression of cyclin D1 and survivin of osteosarcoma cells. Jeon et al also reported that ginkgetin inhibits cell growth through cell survival-related genes (cyclin D1 and survivin) in prostate DU-145 cancer cells (18). Therefore, the results provide new insight into the inhibition of cell survival-related genes (cyclin D1 and survivin) in the process of ginkgetin on osteosarcoma cells.

There are 18 subtypes in the PARP family, with PARP-1 having the largest proportion of the family and over $90 \%$ functions. These functions include mediated DNA repair and cell energy consumption pool, causing cellular dysfunction and death, and promoting inflammation gene transcription (24). Griffin et al (25) first reported that the cytotoxic activity of sulfuric acid dimethyl ester can be enhanced in the process of DNA excision repair by attenuating the activity of PARP, which shows that it can be used as a sensitizer in cancer therapy together with cytotoxic drugs $(25,26)$.

Administration of ginkgetin at 30 or $40 \mu \mathrm{M}$ significantly suppressed the total PARP protein expression in the osteosarcoma cells. You et al reported that ginkgetin induces apoptosis through cleavages of PARP in PC-3 prostate cancer cells (10). Our findings suggest that ginkgetin induces apoptosis through suppression of PARP in osteosarcoma cells.

To the best of our knowledge, this is the first study to identify that ginkgetin is highly effective in osteosarcoma cells, inhibits cell growth, increases cytotoxicity and induces the cell apoptosis of osteosarcoma cells. These results provide new insight into the action of ginkgetin, which potently inhibits the STAT3, caspase, cyclin D1, survivin and PARP signaling pathway. Therefore, our findings indicate that ginkgetin has a potential role in the treatment of osteosarcoma cells.

\section{References}

1. Bacci G, Gherlinzoni F, Picci P, et al: Adriamycin-methotrexate high dose versus adriamycin-methotrexate moderate dose as adjuvant chemotherapy for osteosarcoma of the extremities: a randomized study. Eur J Cancer Clin Oncol 22: 1337-1345, 1986.

2. Burdach S, van Kaick B, Laws HJ, Ahrens S, Haase R, Körholz D, Pape H, Dunst J, Kahn T, Willers R, et al: Allogeneic and autologous stem-cell transplantation in advanced Ewing tumors. An update after long-term follow-up from two centers of the European Intergroup study EICESS. Stem-Cell Transplant Programs at Düsseldorf University Medical Center, Germany and St. Anna Kinderspital, Vienna, Austria. Ann Oncol 11: $1451-1462,2000$

3. Kong CB, Kim MS, Lee SY, Cho WH, Song WS, Lee JA, Yoo JY, Chung SH and Jeon DG: Prognostic effect of diaphyseal location in osteosarcoma: A cohort case-control study at a single institute. Ann Surg Oncol 16: 3094-3100, 2009.

4. Ferrari S, Smeland S, Mercuri M, Bertoni F, Longhi A, Ruggieri P, Alvegard TA, Picci P, Capanna R, Bernini G, et al; Italian and Scandinavian Sarcoma Groups: Neoadjuvant chemotherapy with high-dose ifosfamide, high-dose methotrexate, cisplatin, and doxorubicin for patients with localizeld osteosarcoma of the extremity: A joint study by the Italian and Scandinavian Sarcoma Groups. J Clin Oncol 23: 8845-8852, 2005.

5. Lee JA, Choi SY, Kang HJ, Lee JW, Kim H, Kim JH, Sung KW, Shin HY, Ahn HS and Park KD: Treatment outcome of osteosarcoma after bilateral retinoblastoma: A retrospective study of eight cases. Br J Ophthalmol 98: 1355-1359, 2014.

6. Su Y, Sun CM, Chuang HH and Chang PT: Studies on the cytotoxic mechanisms of ginkgetin in a human ovarian adenocarcinoma cell line. Naunyn Schmiedebergs Arch Pharmacol 362: 82-90, 2000.

7. Wang YQ, Wang MY, Fu XR, Peng-Yu, Gao GF, Fan YM, Duan XL, Zhao BL, Chang YZ and Shi ZH: Neuroprotective effects of ginkgetin against neuro-injury in Parkinson's disease model induced by MPTP via chelating iron. Free Radic Res: Jul 1, 2015 (Epub ahead of print).

8. Lim H, Son KH, Chang HW, Kang SS and Kim HP: Effects of anti-inflammatory biflavonoid, ginkgetin, on chronic skin inflammation. Biol Pharm Bull 29: 1046-1049, 2006.

9. Zhang Y, Shi S, Wang Y and Huang K: Target-guided isolation and purification of antioxidants from Selaginella sinensis by offline coupling of DPPH-HPLC and HSCCC experiments. J Chromatogr B Analyt Technol Biomed Life Sci 879: 191-196, 2011.

10. You OH, Kim SH, Kim B, Sohn EJ, Lee HJ, Shim BS, Yun M, Kwon BM and Kim SH: Ginkgetin induces apoptosis via activation of caspase and inhibition of survival genes in PC-3 prostate cancer cells. Bioorg Med Chem Lett 23: 2692-2695, 2013.

11. Iwata S, Ishii T, Kawai A, Hiruma T, Yonemoto T, Kamoda H, Asano $\mathrm{N}$ and Takeyama M: Prognostic factors in elderly osteosarcoma patients: A multi-institutional retrospective study of 86 cases. Ann Surg Oncol 21: 263-268, 2014. 
12. Boye K, Del Prever AB, Eriksson M, Saeter G, Tienghi A, Lindholm P, Fagioli F, Skjeldal S, Ferrari S and Hall KS: High-dose chemotherapy with stem cell rescue in the primary treatment of metastatic and pelvic osteosarcoma: Final results of the ISG/SSG II study. Pediatr Blood Cancer 61: 840-845, 2014.

13. Wang X, Goldstein D, Crowe PJ and Yang JL: Impact of STAT3 inhibition on survival of osteosarcoma cell lines. Anticancer Res 34: 6537-6545, 2014.

14. Salas S, Jiguet-Jiglaire C, Campion L, Bartoli C, Frassineti F, Deville JL, Maues De Paula A, Forest F, Jézéquel P, Gentet JC, et al: Correlation between ERK1 and STAT3 expression and chemoresistance in patients with conventional osteosarcoma. BMC Cancer 14: 606, 2014.

15. Chen H, Aksoy I, Gonnot F, Osteil P, Aubry M, Hamela C, Rognard C, Hochard A, Voisin S, Fontaine E, et al: Reinforcement of STAT3 activity reprogrammes human embryonic stem cells to naive-like pluripotency. Nat Commun 6: 7095, 2015.

16. Yu H, Lee H, Herrmann A, Buettner R and Jove R: Revisiting STAT3 signalling in cancer: New and unexpected biological functions. Nat Rev Cancer 14: 736-746, 2014

17. Liu J, Wei W, Guo CA, Han N, Pan JF, Fei T and Yan ZQ: Stat3 upregulates leucine-rich repeat-containing g protein-coupled receptor 4 expression in osteosarcoma cells. Biomed Res Int 2013: 310691, 2013.

18. Jeon YJ, Jung SN, Yun J, Lee CW, Choi J, Lee YJ, Han DC and Kwon BM: Ginkgetin inhibits the growth of DU-145 prostate cancer cells through inhibition of signal transducer and activator of transcription 3 activity. Cancer Sci 106: 413-420, 2015.
19. Huang J, Lyu H, Wang J and Liu B: MicroRNA regulation and therapeutic targeting of survivin in cancer. Am J Cancer Res 5: 20-31, 2015.

20. Nemec KN and Khaled AR: Therapeutic modulation of apoptosis: Targeting the BCL-2 family at the interface of the mitochondrial membrane. Yonsei Med J 49: 689-697, 2008.

21. Rautureau GJ, Day CL and Hinds MG: Intrinsically disordered proteins in bcl-2 regulated apoptosis. Int J Mol Sci 11: 1808-1824, 2010.

22. Jiang L, Wang P, Chen L and Chen H: Down-regulation of FoxM1 by thiostrepton or small interfering RNA inhibits proliferation, transformation ability and angiogenesis, and induces apoptosis of nasopharyngeal carcinoma cells. Int J Clin Exp Pathol 7: 5450-5460, 2014

23. Ma YP, Zou P, Xiao J and Huang SA: Expression of survivin in cord blood CD34 ${ }^{+}$stem/progenitor cells and its significance. Zhonghua Xue Ye Xue Za Zhi 24: 238-240, 2003 (In Chinese).

24. Langelier MF and Pascal JM: PARP-1 mechanism for coupling DNA damage detection to poly(ADP-ribose) synthesis. Curr Opin Struct Biol 23: 134-143, 2013.

25. Griffin RJ, Pemberton LC, Rhodes D, Bleasdale C, Bowman K, Calvert AH, Curtin NJ, Durkacz BW, Newell DR, Porteous JK, et al: Novel potent inhibitors of the DNA repair enzyme poly(ADP-ribose)polymerase (PARP). Anticancer Drug Des 10: 507-514, 1995.

26. Yang F, Nam S, Zhao R, Tian Y, Liu L, Horne DA and Jove R: A novel synthetic derivative of the natural product berbamine inhibits cell viability and induces apoptosis of human osteosarcoma cells, associated with activation of JNK/AP-1 signaling. Cancer Biol Ther 14: 1024-1031, 2013. 